\title{
Erratum to: The economic impact of future increase in tropical cyclones in Japan
}

\author{
Christian Webersik • Miguel Esteban • Tomoya Shibayama
}

Published online: 5 June 2010

(C) Springer Science+Business Media B.V. 2010

\section{Erratum to: Nat Hazards \\ DOI 10.1007/s11069-010-9522-9}

The following paragraphs should be changed due to a handling error of the manuscript.

1st paragraph:

Ongoing research projects aim now at geo-coding socio-economic key indicators, such as economic income or population density. ${ }^{3}$ A...

"World Bank report on Natural Disaster Hotspots, for example, highlights areas with a relatively high loss risk from one or more natural disasters including tropical cyclones, floods, droughts, volcanoes, earthquakes and landslides (Dilley et al. 2005). Spatial environmental data (on different types of land cover, for example forests) are available through global environmental assessments, such as the Millennium Ecosystem Assessment. Data on natural hazards, combined with subnational distribution of population, economic income, topography and land use can help to identify areas that are at a relatively high economic loss risk due to natural hazards, such as tropical cyclones."

2nd paragraph:

"In the present research, however, only a fairly simplistic socio-economical model was taken into account, which does not consider future socio-economic changes or economic growth. Though this could be seen as fairly simplistic, the Japanese population and

The online version of the original article can be found under doi:10.1007/s11069-010-9522-9.

C. Webersik $(\bowtie)$

Centre for Development Studies, University of Agder, Gimlemoen 17,

Servicebox 422, 4604 Kristiansand, Norway

e-mail: christian.webersik@uia.no

M. Esteban - T. Shibayama

Department of Civil and Environmental Engineering, Waseda University,

Ookubo, Shinjuku-ku, Tokyo 169-8555, Japan

e-mail: esteban.fagan@gmail.com

T. Shibayama

e-mail: shibayama@waseda.jp 
economic performance has been stagnating for the last two decades, and it is not clear what will happen in the future.

Also, although on the one hand growing incomes increase resilience to the impact of tropical cyclones, on the other hand growing wealth and population growth exposes more people and more assets to cyclones, increasing the overall loss potential."

3rd paragraph:

"To model histograms of the maximum expected surface wind speed, Knutson and Tuleya (2004) used four different convection schemes. Although each simulation is based on a different type of hurricane simulation generating slightly different maximum wind speeds, their research demonstrates that an increase in both cyclone intensity and nearstorm rainfall can be associated with an increase in Surface Sea Temperature (SST).

Accordingly, Fig. 2 depicts the expected hurricane frequency distribution that would result from an increasing maximum wind intensity. The method in this article computes the 2085 frequency distribution into a probability distribution curve. The latter is used to modify the intensity of historical storms. Hence, the simulation randomly generates an "intensity multiplier" based on this probability distribution curve. This intensity multiplier modifies and adjusts maximum wind speeds of the historical storms throughout their lifespan. As a result, the maximum wind"

... speeds of a hypothetical future tropical cyclone can be modelled. 